\title{
Minorias no contexto de trabalho: uma análise das representações socais de estudantes universitários ${ }^{1}$
}

\section{Minorities in the work context: an analysis of the social representations of university students}

\author{
Luciana Maria Maia² \\ lara Andrade de Oliveira ${ }^{3}$ \\ Luiza Barbosa Porto Lima ${ }^{4}$ \\ Priscila de Oliveira Parente ${ }^{5}$ \\ Lana Soares Silva ${ }^{6}$
}

\begin{abstract}
RESUMO: O trabalho objetiva identificar como estudantes universitários representam a participação de minorias sociais no contexto de trabalho. Dados oficiais revelam que alguns grupos sociais são discriminados, considerando as oportunidades de trabalho, os espaços que ocupam e os salários que recebem. Pesquisas apontam que boa parte desse problema pode ser analisado a partir das representações sociais que sustentam o preconceito contra esses grupos. O preconceito pode ser compreendido como uma forma de relação que se manifesta por atitudes negativas, por comportamentos hostis e discriminatórios dirigidos a membros de minorias sociais. Realizou-se uma pesquisa com 83 estudantes universitários, por meio da Técnica de Associação Livre de Palavras, com os termos indutores "mulher", "negro", "homossexual", "egresso do sistema prisional", "pessoa com deficiência" e "pessoa com transtorno mental", todos seguidos da expressão "no contexto de trabalho". Para análise, utilizou-se o Iramuteq, especificamente a análise prototípica, considerando separadamente cada minoria. Os resultados são apresentados tendo em vista os elementos do Núcleo Central (NC) e das Zonas Periféricas (ZP). No NC, o preconceito parece ser reconhecido de forma flagrante para negros, homossexuais, pessoas com transtornos mentais, egressos do sistema prisional. Em contrapartida, para mulheres e pessoas com deficiência, as representações sugerem um preconceito velado. Nas zonas periféricas observam-se mudanças graduais que ficam mais claras na zona de contraste, indicando a emergência de representações que reconhecem a discussão e a luta por igualdade de direitos para alguns grupos. Não obstante, para outros, as representações ainda expressam os obstáculos à inclusão social.
\end{abstract}

Palavras-chave: preconceito; exclusão; representações sociais; minorias sociais; mercado de trabalho.

ABSTRACT: This paper aims to identify how university students represent minorities participation in the work context. Data reveals that some social groups are discriminated against, considering job opportunities, positions and the salaries received by them. Research indicates that much of the problem can be analyzed from the social representations that have sustained prejudice on minority groups. Prejudice can be understood as a form of relationship manifested by negative and derogatory attitudes and by hostile and discriminatory behavior. We had an 83 university students

\footnotetext{
1 Financiamento CNPq e Fundação Edson Queiroz.

${ }^{2}$ Professora do Programa de Pós-Graduação em Psicologia da Universidade de Fortaleza - Fortaleza, CE, Brasil. E-mail: lumariamaia@hotmail.com

${ }^{3}$ Mestranda em Psicologia e Bolsista FUNCAP da Universidade de Fortaleza - Fortaleza, CE, Brasil.

${ }^{4}$ Graduanda em Psicologia e Bolsista PIBIC/FEQ da Universidade de Fortaleza - Fortaleza, CE, Brasil.

${ }^{5}$ Graduanda em Psicologia e Bolsista PIBIC/CNPq da Universidade de Fortaleza - Fortaleza, CE, Brasil.

${ }^{6}$ Graduanda em Psicologia e Bolsista PIBIC/FUNCAP da Universidade de Fortaleza - Fortaleza, CE, Brasil.
} 
study, using the Free Words Association Technique, with the terms "woman", "black", "homosexual", "egress from the prison system", "person with disability" and "person with mental disorder", all followed by the expression "in the work context". To the analysis, we used Iramuteq, specifically, a prototypical analysis, considering separately each minority. The results are presented in elements of Central Core (CC) and Peripheral Zones (PZ). In the CC, prejudice seems to be blatantly recognized to black people, homosexuals, people with mental disorders, egresses from the prison system. By contrast, for women and people with disabilities, the representations suggested a subtle prejudice. In the periphery zones, there were gradual changes, clearer in the contrast zone, indicating an emergence of representations that recognize a discussion and a struggle for equal rights for some of the groups. Nevertheless, to other groups the representations still express the obstacles to social inclusion.

Keywords: prejudice; exclusion; social representations; social minorities; job market.

\section{Introdução}

Desde as últimas décadas do século $X X$, o mundo do trabalho tem passado por significativas transformações que têm contribuído para aumento das taxas de desemprego, diminuição do emprego assalariado e generalizados postos de trabalho precarizados (Pochmann, 2012). As relações de trabalho, ao longo da história e em diferentes sociedades, têm permitido analisar as condições nas quais os direitos humanos têm ou não sido respeitados (Martins \& Pires, 2016). Esse é um fenômeno complexo que ocorre em diversos países, incluindo o Brasil, e as análises evidenciam padrões de participação e de desenvolvimento laborais desiguais em relação a setores da economia, a países e regiões, bem como a grupos sociais. Isso significa afirmar que há indivíduos para os quais os efeitos dessa realidade são mais devastadores em função da natureza da atividade que desenvolvem, dos espaços geográficos que ocupam ou dos grupos sociais a que pertencem (Guimarães, 2012).

Esses grupos são considerados minorias sociais, não pelo caráter quantitativo, mas pela condição de discriminação e/ou marginalização que vivenciam, em decorrência de aspectos econômicos, sociais, culturais, físicos ou religiosos (Hernandez, Accorssi \& Guareschi, 2013). São grupos que vivenciam uma realidade de exclusão, enquanto processo simbólico que enfraquece laços sociais, priva ou dificulta a participação de seus membros em diversos contextos e instituições sociais (Campos, 2003).

No contexto brasileiro, tendo como referência indicadores que refletem a situação de vulnerabilidade e exclusão social (Instituto Brasileiro de Geografia e Estatística [IBGE], 2011; Pinheiro, Fontoura, Querino, Bonetti, \& Rosa, 2008) e pesquisas acadêmicas, compõem grupos minoritários mulheres, negros, pessoas LGBT, pessoas com deficiência, pessoas com transtornos mentais, entre outros. Em relação à inserção no mercado de trabalho, a situação de desvantagem vivenciada por esses grupos é evidenciada, por exemplo, na menor remuneração, em comparação às recebidas por outros, tais como brancos, homens e heterossexuais, mesmo quando equivalem em nível de escolaridade (Costa, 2010; Garcia \& Souza, 2010; Lopes, 2010; Vasconcelos, 2010).

Além das questões econômicas, do ponto de vista social, o trabalho assume um lugar central para homens e mulheres na contemporaneidade, possibilitando a compreensão de aspectos subjetivos e de problemas sociais (Heloani \& Capitão, 2003; Morin, Tonelli, \& Pliopas, 2007). Os ambientes de trabalho, enquanto organizações sociais, reproduzem condições e relações de trabalho marcadas por situações de preconceito e discriminação, tais como as existentes na sociedade de um modo geral (Belo \& Camino, 2012). O preconceito, enquanto 
fenômeno que existe no mundo inteiro e em todos os tempos, tem contribuído para cercear os direitos e a dignidade humana, determinando e perpetuando desigualdades e injustiças e contribuindo para a exclusão social (Camino, Silva \& Machado, 2004).

Na psicologia social, o conceito de preconceito é inicialmente apresentado por Allport (1954), como uma atitude hostil contra uma pessoa simplesmente por pertencer a um grupo desvalorizado socialmente. Situando no âmbito das relações intergrupais, o preconceito pode ser compreendido como forma de relação que se desenvolve no interior dos grupos dominantes, que se manifesta por atitudes negativas e depreciativas e por comportamentos hostis e discriminatórios em relação aos membros de grupos minoritários, enquanto membros desses grupos. Esta definição pressupõe a compreender o preconceito em cada contexto social, a partir das imagens elaboradas pelos grupos a respeito dos outros grupos e dos significados psicológicos e ideológicos construídos nos contextos das ideologias de cada sociedade (Camino \& Pereira, 2000; Lacerda, Pereira \& Camino 2002).

Elementos comuns aos vários tipos de preconceito, seja de cor, gênero, orientação sexual, idade, entre outros, são: a hierarquização de diferenças; a antipatia por uma pessoa que pertence a um grupo desvalorizado socialmente; a visão homogênea sobre membros de um grupo; e uma resistência a fatos que evidenciam a não confirmação de crenças negativas sobre o grupo alvo de preconceito (Lima, 2013).

\section{Preconceito e representações sociais}

No âmbito da Psicologia social, a Teoria das Representações Sociais (TRS) tem se constituído um campo fecundo para os estudos sobre preconceito, ao permitir analisar as interações entre uma minoria discriminada e uma maioria discriminadora (Moscovici, 2009), considerando a articulação entre os sistemas cognitivo e afetivo, a nível individual, e os sistemas relacionais e societais (Doise, 2002). A TRS possibilita a compreensão dos mecanismos que, a nível individual, grupal e social, contribuem para manter as formas e as experiências de exclusão (Jodelet, 1996); e, desse modo, apresenta-se como um instrumento adequado à análise e busca de soluções para os problemas sociais, contemplando diferentes atores envolvidos no tecido social - indivíduos excluídos, diferentes agentes sociais e instituições (Abric, 1996).

Enquanto conceito, as representações sociais compreendem sistemas de explicações, crenças e ideias que permitem ao indivíduo evocar um dado acontecimento, pessoa, grupo ou objeto. As representações são construídas de forma coletiva, resultam da interação social, são compartilhadas por grupos de indivíduos (Moscovici, 2005, 2012), e funcionam como teorias de senso comum para orientar práticas sociais (Jodelet, 2001).

Partindo do que foi exposto e com o intuito de identificar como se estruturam as representações sociais acerca dessas minorias, tendo em vista a participação no contexto de trabalho, adotou-se a abordagem estrutural das representações sociais, especificamente, os pressupostos da Teoria do Núcleo Central (Abric, 2001; Sá, 2002). Segundo esta teoria, em relação às características estruturais, as representações sociais são, ao mesmo tempo, estáveis e móveis, fixas e flexíveis, e expressam tanto o consenso, como as idiossincrasias interindividuais (Sá, 2002). Desse modo, enquanto unidade, a representação social é constituída por um núcleo central e por um sistema periférico. 
O núcleo central é formado por conteúdos que refletem os valores do grupo, a memória coletiva e as condições sócio históricas. Esse sistema expressa o conteúdo consensual, fortemente compartilhado pelo grupo e, por isso, mais estável e resistente a mudanças (Abric, 2001). O sistema periférico, por sua vez, reúne elementos que promovem a relação entre a realidade concreta e o núcleo central., estão mais ligados ao contexto imediato, por isso são mais flexíveis e podem trazer informações novas, que funcionam como um sistema de defesa para as representações, uma vez que quando ocorrem mudanças no contexto, a representação não se modifica por completo (Abric, 2001).

As representações compartilhadas acerca das minorias e da participação desses grupos em contextos de trabalho têm se transformado ao longo da história, tendo em vista os processos culturais, políticos e econômicos que as acompanham. Essas transformações podem ser compreendidas, também, como um processo decorrente do fortalecimento das minorias sociais por meio da formação e valorização de uma identidade, fenômeno que Tajfel (1982) chama de criatividade das minorias. Esses grupos buscam reavaliar as características consideradas desfavoráveis, interna e externamente, de maneira a transformar essa valoração, procurando no passado do grupo as tradições e atributos para serem revitalizados e valorizados. Desse modo, os aspectos que singularizam as minorias em relação à maioria hegemônica não os impossibilitam de constituírem-se enquanto corpo social, capaz e ativo de reivindicar por direitos e garantias previstas na ordem jurídico-social (Hernandez et al., 2013).

Retomando a discussão sobre as minorias no contexto de trabalho, destaca-se que, considerando o contexto atual, as representações são construídas em meio aos avanços na legislação, ao desenvolvimento da ciência e da tecnologia e, ao mesmo tempo, à realidade e às práticas sociais excludentes. Os membros dessas minorias são indivíduos reconhecidos como iguais, têm direitos garantidos, podem ter equiparadas suas condições de participação, mas permanecem em condições sociais desvantajosas. Desse modo, podemos pensar que, embora a palavra inclusão tenha invadido as discussões cotidianas, não se constituiu, na prática, em realidade efetiva para minorias sociais. Trata-se, muito mais, de um discurso, uma retórica distante do seu real significado, que tem sido teorizado na Psicologia social relacionado às novas formas de preconceito (Turra \& Venturi, 1995; Pereira, Torres \& Almeida, 2003; Lima \& Vala, 2004; Lima, 2013). As teorias sobre as novas formas de preconceito propõem que, cedendo às pressões sociais, os indivíduos expressam o preconceito de modo velado, sem se oporem abertamente à norma social, embora, no foro íntimo, não tenham internalizado novos valores e conservem atitudes preconceituosas, enraizadas em suas estruturas mentais (Camino et al., 2004).

Considerando o que foi apresentado, julga-se importante compreender o papel das representações sociais na manutenção do preconceito e da discriminação de minorias sociais. Desse modo, este artigo tem como objetivo identificar como estudantes universitários representam a participação de minorias sociais no contexto de trabalho. 


\section{Método}

\section{Participantes}

Participaram deste estudo 83 estudantes universitários de diferentes cursos de graduação de uma universidade privada da cidade de Fortaleza, com idades variando entre 18 e 52 anos $(\overline{\mathrm{X}}=24 ; D P=6,41)$, sendo a maioria $(57,8 \%)$ do sexo feminino.

\section{Instrumento}

Com o objetivo de identificar o campo semântico relativo às concepções sobre a participação de minorias no contexto de trabalho, os participantes responderam a um instrumento de evocação, com base na Técnica de Associação Livre (TALP), sobre minorias no contexto de trabalho, utilizando os termos indutores: "negros", "egressos do sistema prisional", "homossexuais", "mulheres", "pessoas com deficiência" e "pessoas com transtorno mental". Os participantes foram solicitados a escrever, em local específico, as três palavras que lhe viessem à mente sobre o termo indutor. Além dos testes de associação livre, foram incluídas questões de caráter sociodemográfico com o intuito de identificar o sexo e a idade dos participantes.

\section{Procedimento}

Os participantes foram abordados individualmente, em locais de convivência, de uma universidade privada da cidade de Fortaleza, e convidados a participar da pesquisa. Aqueles que aceitaram, foram informados que a pesquisa tinha como objetivo "conhecer o que pensam universitários sobre a participação de alguns grupos sociais no contexto de trabalho", e esclarecidos acerca das questões éticas. Em seguida, os participantes preencheram o instrumento de pesquisa, de forma individual e em local reservado. Essa pesquisa segue as Resoluções 466/2012 e 510/2016 tendo sido submetida e aprovada pelo Comitê de Ética da UNIFOR, conforme parecer 1.525.237/16.

\section{Análise dos dados}

Para análise dos resultados, utilizou-se o Iramuteq, que consiste em um software que possibilita a análise de dados textuais por meio de recursos estatísticos e gráficos (Ratinaud, 2009). Previamente, as palavras evocadas passaram por um processo de lematização, em que se procurou padronizá-las quanto ao gênero, número e classe gramatical, bem como em alguns casos, pela equivalência de conteúdo (Wachelke \& Wolter, 2011). Em seguida, processou-se a Análise de Frequências Múltiplas, para acessar a frequência absoluta e relativa das palavras na matriz (Camargo \& Justo, 2013). Para a análise da estrutura das representações sociais, foram realizadas Análises Prototípicas (Vergès, 1992) para cada um dos estímulos indutores. A Análise Prototípica baseia-se no cálculo da frequência e ordem das palavras evocadas, gerando um quadro com quatro quadrantes. No quadrante superior esquerdo, compondo o Núcleo Central (NC) da representação social, encontram-se as palavras com alta frequência e baixa ordem de evocação - palavras que foram apresentadas por um grande número de participantes e evocadas prontamente (normalmente mencionadas no 
primeiro momento). O NC é composto pelos principais elementos da representação, pouco sensíveis ao contexto imediato e ligados à história do grupo.

Nos quadrantes da direita encontram-se os elementos periféricos: o superior, denominado de Primeira Periferia (PP), reúne as palavras mencionadas com alta frequência e alta ordem de evocação (mencionadas por um grande número de participantes, mas lembradas no segundo ou terceiro momento). Neste quadrante encontram-se representações individuais, mas que podem ter elementos considerados centrais. Já no quadrante inferior, denominado de Segunda Periferia (SP), estão as palavras que tiveram uma baixa frequência de evocação e foram mencionadas de forma tardia (no segundo ou terceiro momento). Neste quadrante estão reunidos elementos que podem fazer parte de realidades mais específicas do grupo. As palavras do quadrante esquerdo inferior devem ser analisadas como elementos contrastantes - Zona de Contraste (ZC). Este quadrante é composto por elementos com baixa frequência de evocação, mas que foram prontamente mencionados. Os elementos que compõem a ZC podem se opor aos presentes no NC, caracterizarem-se como importantes para alguns indivíduos do grupo, ou apresentarem palavras que são a continuação da PP (Camargo \& Justo, 2013; Wachelke \& Wolter, 2011). A representação gráfica desses quadrantes pode ser observada na Figura 1.

\begin{tabular}{|c|c|}
\hline Núcleo Central & 1a Periferia \\
Frequência alta & Frequência alta \\
Prontamente evocados & Menos prontamente evocados \\
\hline Zona de Contraste & 2a Periferia \\
Frequência baixa & Frequência baixa \\
Prontamente evocados & Menos prontamente evocados \\
\hline
\end{tabular}

Figura 1 - Representação gráfica da Análise Prototípica

\section{Resultados e discussões}

O número de evocações obtido por estímulo indutor foi: 119 para Negros, 141 para Homossexuais, 125 Mulheres, 124 para Pessoas com deficiência, 142 para Pessoas com transtornos mentais e 124 para Egressos do Sistema Prisional. Cabe salientar que o número de evocações totais é menor do que a soma das palavras evocadas por categorias devido às repetições.

A frequência mínima considerada para a inclusão das palavras na análise prototípica foi de cinco, pouco mais de $2 \%$ do tamanho da amostra. Em relação à determinação dos pontos de corte para as coordenadas dos quadrantes, optou-se por manter os padrões automáticos do software. Deste modo, cada categoria possuiu um ponto de corte diferenciado para frequência e ordem média de evocação (OME), dado a variabilidade no número de evocações por categoria, conforme demonstrado na Tabela 1. 
Tabela 1 - Análise Prototípica para as seis minorias sociais

\begin{tabular}{|c|c|c|c|c|c|c|c|}
\hline Categori & & Evocação & $f$ & OME & Evocação & $f$ & OME \\
\hline \multirow{6}{*}{ 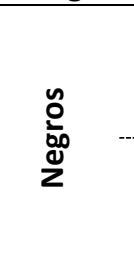 } & \multirow{3}{*}{$f>9,56$} & \multicolumn{3}{|c|}{$\mathrm{OME}<1,9$} & \multicolumn{3}{|c|}{ OME $>1,9$} \\
\hline & & Força & 12 & 1.8 & Preconceito & 26 & 2.2 \\
\hline & & Racismo & 10 & 1.2 & Igualdade & 10 & 2.1 \\
\hline & \multirow{6}{*}{$f>8,67$} & Direito & 5 & 1.8 & Respeito & 6 & 2.2 \\
\hline & & Normal & 5 & 1 & Conquista & 6 & 2 \\
\hline & & & & & Superação & 6 & 2 \\
\hline \multirow{8}{*}{ 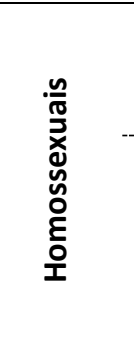 } & & \multicolumn{3}{|c|}{$\mathrm{OME}<1,76$} & \multicolumn{3}{|c|}{ OME > 1,76 } \\
\hline & & Preconceito & 30 & 1,6 & & & \\
\hline & & Discriminação & 11 & 1,6 & & & \\
\hline & \multirow{5}{*}{$f<8,67$} & Normal & 6 & 1,3 & Respeito & 6 & 2,2 \\
\hline & & Igualdade & 5 & 1,4 & Alegria & 5 & 2,2 \\
\hline & & & & & Aceitação & 5 & 1,8 \\
\hline & & & & & Rejeição & 5 & 2,4 \\
\hline & & & & & Dificuldade & 5 & 2,2 \\
\hline \multirow{8}{*}{$\begin{array}{l}\text { d’ } \\
\frac{\grave{d}}{\bar{\Xi}} \\
\bar{\Sigma}\end{array}$} & \multirow{3}{*}{$f>8,91$} & \multicolumn{3}{|c|}{$\mathrm{OME}<1,84$} & \multicolumn{3}{|c|}{ OME $>1,84$} \\
\hline & & Dedicação & 12 & 1,8 & Organização & 24 & 2 \\
\hline & & Competência & 9 & 1,8 & Responsabilidade & 15 & 1.9 \\
\hline & \multirow{5}{*}{$f<8,91$} & Igualdade & 6 & 1,3 & Determinação & 7 & 2.3 \\
\hline & & Preconceito & 5 & 1,4 & Eficiência & 5 & 2 \\
\hline & & Conquista & 5 & 1,4 & & & \\
\hline & & Luta & 5 & 1,8 & & & \\
\hline & & Independência & 5 & 1,8 & & & \\
\hline \multirow{8}{*}{ 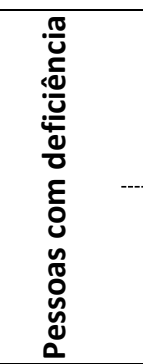 } & \multirow{4}{*}{$f>8,55$} & \multicolumn{3}{|c|}{$\mathrm{OME}<1,97$} & \multicolumn{3}{|c|}{$\mathrm{OME}>1,97$} \\
\hline & & Superação & 15 & 1,9 & Preconceito & 10 & 2,5 \\
\hline & & Oportunidade & 14 & 1,7 & Respeito & 9 & 2,1 \\
\hline & & Dificuldade & 13 & 1,7 & & & \\
\hline & \multirow{4}{*}{$f<8,55$} & Cota & 6 & 1,6 & Igualdade & 7 & 2,3 \\
\hline & & Esforço & 5 & 1,5 & Inteligente & 5 & 2,4 \\
\hline & & & & & Eficiência & 5 & 2,4 \\
\hline & & & & & Acessibilidade & 5 & 2 \\
\hline \multirow{6}{*}{ 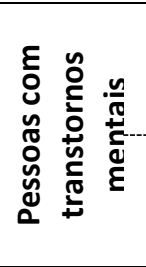 } & \multirow{3}{*}{$f>9,25$} & \multicolumn{3}{|c|}{ OME $<2,03$} & \multicolumn{3}{|c|}{ OME $>2,03$} \\
\hline & & Preconceito & 15 & 1,8 & Oportunidade & 10 & 2,3 \\
\hline & & Dificuldade & 15 & 2 & & & \\
\hline & & Superação & 9 & 2 & Medo & 7 & 2,3 \\
\hline & $f<9,25$ & Paciência & 7 & 1,7 & Respeito & 6 & 2,2 \\
\hline & & & & & Inclusão & 5 & 2,2 \\
\hline \multirow{6}{*}{ 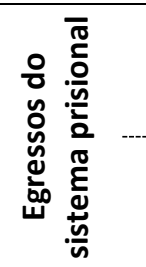 } & & ON & & & OME & & \\
\hline & & Oportunidade & 19 & 1,6 & Preconceito & 26 & 1,9 \\
\hline & $f>13,57$ & Desconfiança & 18 & 1,4 & & & \\
\hline & & Receio & 5 & 1,4 & Medo & 12 & 2,2 \\
\hline & $f<13,57$ & & & & Dificuldade & 8 & 2 \\
\hline & & & & & Superação & 7 & 1,9 \\
\hline
\end{tabular}

Nota: OME (Ordem Média de Evocação).

\section{Negros}

Com relação ao estímulo indutor "negros no contexto de trabalho", as palavras "força" e "racismo" são as que se referem a elementos centrais da representação social. O elemento "preconceito", apesar de não estar no núcleo central, por ter uma ordem de evocação mais alta do que o ponto de corte, parece continuar reforçando a ideia desse quadrante. Os 
elementos periféricos parecem fazer referência a uma busca por "respeito", "conquista" e "superação" do preconceito vivenciado por esse grupo. Também é possível observar o contraste entre esse preconceito racial e o reconhecimento de que o grupo tem "direito" à igualdade como algo "normal" a qualquer outro indivíduo.

A palavra "racismo", como elemento central da representação, parece sugerir o reconhecimento dessa forma de violência no Brasil em relação aos negros, mas não necessariamente indica que os participantes se considerem racistas (Turra \& Venturi, 1995). Em uma perspectiva menos favorável, pode-se pensar que se trata de um fenômeno institucionalizado e naturalizado nas relações sociais (López, 2012).

Outro aspecto que merece ser discutido refere-se à palavra "força" como um dos elementos centrais da representação acerca do negro no contexto de trabalho, que pode ser considerado um termo negativo (Whitley \& Kite, 2010), mas também pode estar relacionada a uma mudança nos estereótipos atribuídos a esse grupo, que passa a incorporar elementos pretensamente positivos (Lima \& Vala, 2004). Ou, ainda, de maneira abstrata, referir-se ao negro como esforçado, tomando o termo em oposição à competência, que seria uma característica dos brancos (Ferreira \& Camargo, 2011; Batista, Leite, Torres, \& Camino, 2014). Esse caráter negativo do termo "força" sustenta-se, ainda, quando se constata sua proximidade com o termo "racismo", podendo ratificar a naturalização do trabalho braçal do negro, herança histórica da escravidão no Brasil (Pereira, 2013).

Dando continuidade à análise do NC, as palavras "preconceito" e "igualdade", evocadas conjuntamente, parecem sustentar uma representação do negro que expressa o conflito existente nas sociedades modernas que, por um lado reconhece a condição de preconceito e discriminação vivenciada por alguns grupos sociais, mas por outro lado, se baseia em uma lógica liberal, expressa em valores meritocráticos. A sociedade defende valores igualitários, mas na prática se opõe a ações que são coerentes com esses valores (Lima, 2002; Lima \& Vala, 2004). Esse conflito tem ajudado a explicar novas expressões do preconceito contra negros, tal como constatado em diversas pesquisas (Camino et al., 2004; Lima, 2013).

Essa discussão parece ser reforçada na oposição entre os termos "direito" e "normal", por um lado, e "racismo" e "força", por outro. De fato, se a inserção do negro no contexto de trabalho fosse algo normal e um direito assegurado, o racismo não deveria aparecer como elemento central da representação acerca desse grupo. Sob outro prisma, a palavra "normal" pode ser pensada pela perspectiva da diferenciação intergrupal - a afirmação da igualdade é o próprio reconhecimento da diferença entre os grupos (Lima, 2002).

Ainda sobre os termos "normal" e "direito", considera-se que estão fortemente atrelados às normais sociais antidiscriminação, que caracterizam as sociedades modernas, as quais reivindicam, no plano das ideias, práticas inclusivas, em que a diversidade assume o caráter de normalidade e a condição de ser diferente, um direito de todos. Em muitos casos, a expectativa de ter assegurado o direito de ser diferente entra em choque com as adversas condições sociais de funcionamento da sociedade em face dos estatutos de igualdade por ela reconhecidos (Cury, 2002).

Essa ideia de contradição é reforçada quando se consideram os elementos individuais e sua relação com a estrutura geral da representação acerca do negro em contextos de trabalho. Desse modo, as palavras "respeito", "conquista" e "superação", que aparecem caracterizando o discurso individual dos participantes, na SP, podem até disfarçar o preconceito racial, 
contudo, quando relacionadas às palavras "racismo" e "preconceito", "igualdade" e "força", que expressam o discurso social dominante, parecem reforçar o racismo e a discriminação.

\section{Homossexuais}

De modo similar ao que ocorre com os negros, com respeito ao estímulo indutor "homossexuais no contexto de trabalho", as palavras "preconceito" e "discriminação" constituem elementos centrais dessa representação. É importante destacar que essa representação parece ser tão forte, que não apareceram elementos na PP que a proteja. Em outras palavras, o reconhecimento e a naturalização do preconceito e da discriminação experienciados pelos homossexuais no contexto de trabalho são aspectos fortemente compartilhados socialmente. Em relação às evocações da SP, "respeito", "alegria", "rejeição" e "dificuldade", parecem estar relacionadas às experiências cotidianas dos participantes com esse grupo, e que se caracterizam por sentimentos contraditórios e pelo estereótipo do homossexual como uma pessoa alegre. Na ZC, tal como ocorreu para os negros, aparece a afirmação da "igualdade" e a noção desse grupo como "normal", contrapondo-se ao preconceito e discriminação que vivenciam.

Como ocorreu em relação aos negros, as representações de universitários sobre homossexuais no contexto de trabalho parecem indicar um fenômeno institucionalizado, seja o preconceito em si ou a discussão que dele decorre (Pocahy, 2007). A centralidade dessa representação do homossexual, a partir dos termos "preconceito" e "discriminação", pode, também, ser relacionada à própria invisibilidade desse grupo. É possível supor que os universitários não reconhecem os homossexuais na condição de trabalhadores ou, ainda, os próprios homossexuais ficam invisíveis ao se "manterem no armário", ou seja, ao esconderem sua orientação sexual, como estratégia utilizada para evitar a discriminação, quando percebem que no ambiente de trabalho não há um sistema de apoio, respeito ou aceitação, ou, adotam tal estratégia por acreditar que sua orientação sexual pode interferir na sua carreira e na sua permanência no emprego (Ferreira, 2007). A possibilidade de esconder a orientação homossexual é apontada como um importante fator de diferenciação das vivências de preconceito dos homossexuais em contextos de trabalho quando comparados às experiências de outros grupos (Medeiros, 2007).

Ainda pensando acerca da invisibilidade que esse grupo vivencia no contexto de trabalho, pode-se entender que ao responderem ao estimulo indutor homossexuais, os universitários parecem se referir ao profissional "gay". Essa possibilidade é reforçada quando se constata que, comparados a outros grupos LGBT (travestis, transexuais, lésbicas), os gays são menos discriminados em contextos de trabalho (Carrara, Facchini, Simões \& Ramos, 2006).

Ampliando a análise, de forma geral, percebe-se a oposição das palavras "normal" e "igualdade" com as "preconceito" e "discriminação". Essa oposição lança uma reflexão acerca do conflito dos valores sociais da modernidade, atravessada pelas ações e políticas afirmativas que reforçam socialmente a normalidade e a luta pela igualdade dos homossexuais quanto a sua participação no mercado de trabalho, mas que na prática, os valores heteronormativos é que são priorizados, dando então lugar ao preconceito e discriminação. A simples ativação da norma não é suficientemente eficaz para a redução do preconceito (Pereira, 2009), que faz uso de crenças sociais negativas relacionadas à moral, religião e ciência, com a finalidade de produzir uma hierarquia sexual garantida pelas práticas sociais que atribuem à 
heteronormatividade um lugar de normatização e regulação das ações humanas (Prado \& Machado, 2008).

A menção pelos universitários das palavras "normal" e "igualdade" supõe um processo de diferenciação em relação ao grupo de homossexuais, já que grupos majoritários não precisam ser afirmados como iguais. Pode-se traçar um paralelo com os resultados obtidos quanto ao grupo dos negros, em que a palavra "normal" é discutida na perspectiva da diferenciação intergrupal, uma vez que, a afirmação da igualdade é o próprio reconhecimento da diferença entre grupos (Lima, 2002).

A palavra "alegre" não é necessariamente representativa do contexto laboral, mas expressa um estereótipo que estigmatiza esse grupo. A atribuição de estereótipos pode ser discutida por relacionada ao humor como prática de preconceito nas organizações, tendo em vista que esses atributos, que se pretendem positivos, classificam os gays como bemhumorados, divertidos e engraçados como fatores de aceitação social; além do que esse estereotipo também se apresenta como possibilidade de categorizar o diferente do padrão social e rir de sua condição (Irigaray, Saraiva \& Carrieri, 2010)

\section{Mulheres}

No que se refere ao estímulo indutor "mulheres no contexto de trabalho", as palavras "dedicação" e "competência" aparecem no NC, sugerindo o principal sentido da representação. As palavras "organização" e "responsabilidade" (PP) e "determinação" e "eficiência" (SP) complementam o sentido central dessa representação, conferindo a esse grupo uma imagem pretensamente positiva, de forte competência e eficiência profissional. $\mathrm{Na}$ ZC, as palavras "igualdade", "preconceito", "conquista", "luta" e "independência" se contrapõem a essa visão central.

Considerando a estrutura dessa representação, é possível supor que, para os universitários, o reconhecimento de atributos profissionais e a inserção da mulher no contexto de trabalho estão associados a um processo de luta contra o preconceito, pela independência e igualdade de direitos (Matos \& Borelli, 2012). Importante mencionar que essa relação mais específica com esses atributos foi observada, sobretudo, para as mulheres, não se apresentando de forma tão clara nas representações acerca de outros grupos no contexto de trabalho. Se por um lado, esses achados indicam a uma maior visibilidade da participação laboral feminina; por outro, revelam experiências e anseios compartilhados por jovens, que, no caso dos participantes deste estudo são, em sua maioria, estudantes universitários do sexo feminino.

Outro ponto a ser levantado refere-se ao tipo de mulher que os participantes pensam frente ao estímulo "mulher no contexto de trabalho". É razoável propor que a representação dos universitários está relacionada a um tipo específico de mulher, que já está inserida no mercado de trabalho, não se aplicando à mulher, no geral, independentemente do contexto em que está inserida. Os estudos de Fiske, Cuddy, Glick e Xu (2002), a partir do modelo de conteúdo de estereótipos, apontam que "mulheres de negócios" são categorizadas com alta competência e baixa socialização, aspectos considerados positivos em relação à competência, porém, em nível de socialização, considerados como pontos fracos. O oposto é observado entre mulheres "donas de casa", a quem são atribuídas alta socialização e baixa competência. 
Este fenômeno é discutido como um double bind, duplo laço, que remete a essa ambiguidade: se atuarem como homens, em contextos masculinos, mulheres estão expostas a perder características essenciais da "feminilidade"; se agem como mulheres, em contextos femininos, parecem incapazes e inaptas às situações apresentadas. Nesse sentido, tem-se diferentes atribuições às mulheres dependendo da realidade em que estão inseridas mulheres em contexto público de trabalho e mulheres na esfera privada são representadas de forma diferente (Bourdieu, 2012).

As palavras "organização" e "responsabilidade" também qualificam a inserção laboral, e podem ser discutidas como uma manifestação do sexismo benevolente, que associa à mulher a papéis restritos, mas que, considerando as normas sociais, assumem uma conotação positiva (Glick \& Fiske, 1996). Importante destacar que, nos contextos de trabalho, as características de "organização" e "responsabilidade" podem ser atreladas a tarefas secundárias, não tão relevantes em cargos de liderança, favorecendo para que a mulher permaneça em um lugar de subordinação na hierarquia organizacional e reforçando um processo histórico de exclusão ou participação inferior da mulher, em termos de salário e status, em comparação a do homem (Matos \& Borelli, 2012). De fato, embora a diferença salarial entre homens e mulheres tenha caído, o salário das mulheres permanece inferior aos dos homens, mesmo quando equivalem tempo de estudo e nível de escolaridade (Secretaria de Políticas para as Mulheres, 2015; Comisión Económica para América Latina y el Caribe [CEPAL], 2016).

As palavras "conquista", "luta", "independência", "igualdade" e "preconceito", que aparecem na ZC, parecem sugerir mudanças na representação da mulher no contexto de trabalho e a tensão entre a luta por direitos e o reconhecimento do preconceito. Embora ainda existam significativas diferenças na participação de homens e mulheres no mercado de trabalho, do ponto de vista histórico, não há como negar que as mulheres vêm, paulatinamente, conquistando importantes avanços (Matos \& Borelli, 2012).

\section{Pessoas com deficiência}

No que se refere ao estímulo indutor "pessoas com deficiência no contexto de trabalho", as palavras "superação", "oportunidade" e "dificuldade" parecem dar o sentido central dessa representação. Importante observar que tais evocações refletem contradições e ambivalências em torno da participação desse grupo no mercado de trabalho. Essa interpretação fica ainda mais clara quando se observam os elementos periféricos. Considerando a análise dos quadrantes, observa-se possíveis oposições entre as palavras "preconceito" e "respeito", na PP; "cota" e "esforço", na ZC; e na SP aparecem "igualdade" e "acessibilidade", que se referem a direitos, e "inteligência" e "eficiência", atributos de competência profissional.

A especificidade desses resultados, que sugerem pontos de tensão nas representações acerca desse grupo, pode ser melhor analisada quando se considera que o grupo das pessoas com deficiência é o único para o qual existem cotas de vagas de trabalho há mais de duas décadas nas empresas (Lei $n=8.213 / 91$ ) e, do mesmo modo, reserva em concursos públicos (Lei no 7.853/89). Assim, parece haver um reconhecimento que as pessoas com deficiência são sujeitos de direito, produtivos e capazes de trabalhar, mas a existência das cotas, enquanto políticas afirmativas, acirra o conflito com aqueles sem deficiência e que, no contexto atual de crise e escassas vagas de trabalho, almejam se inserir no mercado e que, 
por isso, competem diretamente com os primeiros. Esse conflito pode ser ainda mais forte entre os estudantes universitários que vivenciam diretamente essa realidade de ingresso no mercado de trabalho, bem como formam o grupo com maior percentual dos que estão fora do mercado de trabalho (Instituto de Pesquisa Econômica Aplicada [IPEA], 2017). O contraponto "Preconceito" e "Respeito" parece uma boa ilustração do conflito em torno da participação das pessoas com deficiência em contextos de trabalho.

Resultados que vão nessa direção são observados em outras pesquisas, quando consideram os discursos de profissionais que trabalham em empresas que admitem pessoas com deficiência (Maia, Camino \& Camino, 2011; Vasconcelos, 2010; Violante \& Leite, 2011) e pelas práticas realizadas nas organizações (Braga \& Pereira, 2017; Coutinho, França, Coura, Medeiros \& Aragão, 2017; Ribeiro \& Carneiro, 2009). As cotas, muitas vezes, são percebidas como oportunidades dadas para esse grupo (Maia et al., 2011; Vasconcelos, 2010; Violante \& Leite, 2011), inclusive para as próprias pessoas com deficiência, que podem considerar o acesso às cotas como um aspecto positivo da deficiência (Vasconcelos, 2010).

Reafirmando essa contradição, a palavra que aparece junto com "oportunidade" é "dificuldade", esta pode ser interpretada em diferentes sentidos. A dificuldade de inserção do próprio grupo no contexto de trabalho, apontada em outras pesquisas a partir dos baixos percentuais de inclusão de pessoas com deficiência no mercado de trabalho (Cartilha do Censo 2010 - Pessoas com Deficiência, 2012; Ribeiro \& Carneiro, 2009). A dificuldade por parte das pessoas com deficiência na execução das suas atividades, como aparece em outras pesquisas (Maia et al., 2011; Vasconcelos, 2010; Violante \& Leite, 2011). A dificuldade da organização se adaptar para receber uma pessoa com deficiência, discutida em pesquisas que afirmam que empresas buscam contratar grupos que exijam o mínimo possível de mudanças no contexto laboral (Maia et al., 2011; Violante \& Leite, 2011). E por fim, em um sentido mais amplo, a dificuldade relacionada à qualidade de vida no trabalho considerada insatisfatória, principalmente no que tange ao salário, carga horária de trabalho, quantidade de trabalho e ascensão profissional (Coutinho et al., 2017).

A palavra superação que tem como pressuposto uma dificuldade a ser enfrentada, pode ser percebida como enaltecimento do grupo minoritário, fenômeno observado também em relação a outras categorias sociais. Essa percepção aparece em outras pesquisas, trazendo a figura do "trabalhador-padrão", por exemplo, na pesquisa de Vasconcelos (2010) todos os chefes e colegas entrevistados enalteceram a pessoa com deficiência destacando-o como um bom trabalhador. Também é possível observar essa característica nas palavras "Inteligência" e "Eficiência", que sugerem uma valorização do grupo.

A palavra "igualdade" aparece nos discursos que falam sobre igualdade, sem considerar as diferenças entre as pessoas (Maia et al., 2011; Violante \& Leite, 2011), por meio desses discursos as pessoas posicionam-se contra as cotas e utilizam-se da justificativa de que tratar determinado grupo de maneira desigual aumentaria o preconceito e a discriminação. Esse discurso pode ser relacionado, também, com as palavras "cota" e "esforço", sendo essa oposição relativa à suposta igualdade já existente entre grupos, assim o esforço deveria ser a maneira de chegar ao mercado de trabalho e não a existência de cotas nas empresas. 


\section{Pessoas com transtornos mentais}

As evocações que aparecem no NC para o estímulo indutor "pessoas com transtornos mentais no contexto de trabalho" são "preconceito" e "dificuldade". Tais elementos parecem evidenciar claramente o desafio de inclusão social desse grupo. Não obstante, na PP aparece a palavra "oportunidade", possivelmente trazendo o sentido da importância de possibilitar oportunidades para esses indivíduos e apresentando a inserção laboral como algo positivo para o grupo. Na SP aparecem as palavras "medo", "respeito" e "inclusão", e na ZC, "superação" e "paciência". Esses termos devem ser compreendidos a partir das mudanças e conflitos produzidos desde a Reforma Psiquiátrica, que, por um lado, se constituem de sentimentos de ameaça e, por outro lado, do reconhecimento acerca da necessidade de inclusão desse grupo.

As palavras presentes no NC junto com "paciência" (ZC) e "medo" (SP), parecem apontar que, mesmo frente às importantes mudanças iniciadas a partir da Reforma Psiquiátrica, a exclusão e a estigmatização desse grupo ainda é uma realidade presente (Figueirêdo, Delevati, \& Tavares, 2014). Essa situação se configura, também, na resistência frente a instrumentos normativos que favorecem a inclusão laboral de portadores de transtornos mentais, a exemplo da Lei no 98.67/99, que atravessou um longo período e enfrentou diversos vetos antes de sua promulgação (Volz et al., 2015). A exclusão das pessoas com transtornos mentais não se limita aos espaços de trabalho, sendo um fenômeno percebido amplamente, inclusive em contextos e situações que deveriam possibilitar sua superação (Costa, Jorge, Coutinho, Costa \& Holanda, 2016; Wagner, Borba \& Silva, 2015).

Apesar dessa imagem negativa acerca da pessoa com transtornos mentais, a palavra "oportunidade" surge como elemento que parece reconhecer a necessidade de inserção, embora, considerando o conjunto das evocações, é possível que o termo se refira à pressão da norma social, que estabelece o direito de todos ao trabalho. Importante esclarecer que o reconhecimento dos direitos desse grupo tem recebido mais atenção, exemplo da inclusão, na Convenção sobre os Direitos das Pessoas com Deficiência (Organização das Nações Unidas [ONU], 2006), da categoria deficiência psicossocial, também chamada deficiência psiquiátrica ou deficiência por saúde mental, no rol de deficiências (Sassaki, 2010). Essa mudança, contudo, não tem se mostrado suficiente para favorecer a inclusão desse grupo (Wagner et al., 2015). Outra hipótese que pode ser levantada sobre o termo "oportunidade" é a conotação positiva que é dada ao trabalho. A importância do trabalho é apontada para além da geração de renda, como processo que favorece a autoafirmação, o relacionamento social, a construção de um lugar de inclusão, ocupação da mente e geração de prazer (Vechi, Chirosi \& Prado, 2017).

A palavra "Superação", tal como ocorreu para as pessoas com deficiência, aparece como elemento que compõe a representação desse grupo, o que permite pressupor que existam dificuldades, mas que essas possam ser ultrapassadas, apresentando uma característica aparentemente positiva para o grupo. A percepção de que a participação de pessoas com transtornos mentais no mercado de trabalho é uma superação, também, foi observada em outros estudos (Salles \& Barros, 2013; Wagner et al., 2015). Uma das pesquisas (Wagner et al., 2015) apresenta a situação de uma pessoa com esquizofrenia que trabalha em um supermercado e que superou as expectativas dos colegas de trabalho. Já outra traz o discurso de profissionais de saúde e de pessoas do convívio social que consideram as pessoas com transtornos mentais capazes de superar dificuldades e de contribuir socialmente (Salles \& Barros, 2013). 
A palavra "paciência" parece sugerir que as pessoas que estão em volta desses sujeitos necessitariam dessa característica para que possam se relacionar com tal grupo. Isso pode estar ligado a uma forma de preconceito, levando em consideração o significado da palavra, como uma característica emocional para suportar situações desagradáveis e/ou incômodos sem perder a calma e a concentração. Dessa forma, pode-se supor que o uso dessa palavra está relacionado à atribuição de características negativas às pessoas com transtornos mentais, tal como apontado pela literatura (Costa et al., 2016; Salles \& Barros, 2013; Wagner et al., 2015). O mesmo pode ser observado por meio da palavra "medo", que pode remeter à representação social dessas pessoas como perigosas (Figueirêdo et al., 2014; Salles \& Barros, 2013).

Com relação à palavra "inclusão", pode ser remetida às expectativas de participação social desse grupo. Na pesquisa de Silva e Luissi (2010), por exemplo, os participantes, pessoas que trabalhavam em projetos de inclusão, consideraram que a principal função do trabalho seria a produção de renda, mas para alguns grupos específicos, o trabalho teria uma função terapêutica e a valorização dos sujeitos. A palavra "respeito" ganha um sentido semelhante, também sendo mencionada nas pesquisas supracitadas (Salles \& Barros, 2013; Silva \& Luissi, 2010; Vechi, et al., 2017; Volz et al., 2015; Wagner et al., 2015). A importância de afirmar o "respeito" ao grupo, sugere o reconhecimento de que essa condição não é garantida. Em outras palavras, essa evocação pode indicar o reconhecimento do desrespeito e a evidência do preconceito e discriminação contra esse grupo. Por fim, pode-se pensar, também, que esses discursos, aparentemente inclusivos, seriam uma forma de manter os usuários de saúde mental no trabalho apenas como um processo de reabilitação, que não se caracteriza por uma participação efetiva, favorecendo, desse modo, a construção de uma nova forma de exclusão social (Vechi et al., 2017).

\section{Egressos do sistema prisional}

$\mathrm{Na}$ descrição do estímulo indutor "egressos do sistema prisional no contexto de trabalho", as palavras "oportunidade" e "desconfiança" concentram o sentido central dessa representação. Contudo, vale destacar que embora a palavra "preconceito" não tenha aparecido no NC, por ter apresentado uma ordem média de evocação acima do ponto de corte, foi a palavra que apareceu com maior frequência para esse grupo.

A evocação da palavra "oportunidade" parece relacionada ao movimento de políticas de afirmação que vem sendo instituídas em defesa da reinserção do egresso, a exemplo do programa Começar de Novo (Resolução n. 96/2009 do Conselho Nacional de Justiça [CNJ], 2009), que oferece incentivos para organizações que disponibilizem cursos de capacitação e postos de trabalho para egressos do sistema prisional. Tais oportunidades, no entanto, se mostram limitadas e parecem ser marcadas por "penas invisíveis", que privam egressos dos seus direitos de cidadania. Essas penas, geralmente, têm efeito fora da estrutura de sentença tradicional, sendo impostas por força de lei e não por sentença judicial. Um exemplo de pena invisível é a exigência de certidão negativa de antecedente criminal em seleção de empregos e ocupação de cargos públicos (Dias, 2015; Travis, 2005).

A palavra "desconfiança" evocada para o grupo de egressos sugere o sentido explicitamente negativo da representação acerca desse. Os outros elementos periféricos, "medo", "dificuldade", "superação" e "receio" reforçam a expressão livre do preconceito para 
com o grupo. Esse resultado sugere que é socialmente permitido discriminar esse grupo, uma vez que sua representação envolve um tríplice estigma: moral, por terem se banido da sociedade ao violar a lei; de classe, por serem, em sua maioria, pobres, em uma sociedade meritocrática; e racial, tendo em vista que as pessoas submetidas ao sistema prisional no Brasil são, em sua maioria, jovens negras (Departamento Penitenciário Nacional [DEPEN], 2014). A discriminação contra esse grupo, na forma de humilhação explícita, é amplamente compartilhada e expressa abertamente, já que egressos não são reconhecidos como fazendo parte da categoria de cidadãos e, portanto, são menos merecedores da solidariedade que se estenderia a um membro reconhecidamente pertencente à comunidade (Wacquant, 2003).

\section{Considerações finais}

Neste trabalho, apresentou-se um estudo que objetivou identificar como estudantes universitários representam minorias sociais no contexto de trabalho. Especificamente, pretendeu-se analisar como se estruturam essas representações e, para tanto, partiu-se da abordagem estrutural e, no caso, a Teoria do Núcleo Central. Como pressuposto, considerouse que, embora todos os grupos abordados - negros, mulheres, homossexuais, pessoas com deficiência, pessoas com transtornos mentais e egressos do sistema prisional, sofram preconceito e discriminação no contexto de trabalho, as representações acerca da participação desses grupos se estruturam de modo diferente, tendo em vista as imagens socialmente compartilhadas e as normas sociais, que dependendo do alvo, autorizam formas flagrantes ou encobertas desse processo. De fato, os resultados encontrados vão nessa direção e as representações de grupos tidos como mais estigmatizados, tais como pessoas com transtornos mentais e egressos do sistema prisional, foram formados por elementos explicitamente negativos.

Considerando os principais achados dessa pesquisa, destaca-se que para o grupo negros, a estrutura das representações sugere que o racismo, prontamente reconhecido pelos participantes, é um fenômeno institucionalizado e naturalizado nas relações sociais. Além disso, a evocação de termos pretensamente positivos sugere expressões encobertas de preconceito, hipótese que ganha reforço quando se observa a oposição entre termos localizados em um mesmo quadrante.

De forma semelhante, o preconceito dirigido aos homossexuais foi claramente apontado pelos participantes, indicando um processo de institucionalização desse fenômeno. Sentimentos opostos e a atribuição de estereótipos também compuseram a estrutura das representações acerca dos homossexuais em contextos de trabalho. Além disso, a afirmação da normalidade e igualdade apareceu em contraposição ao reconhecimento do preconceito e discriminação que esse grupo vivencia

No caso das mulheres, destacam-se na estrutura das representações palavras que se referem a atributos de competência organizacional. Esse achado parece ser favorável até uma análise mais detida dos termos evocados, que ratificam o lugar da mulher em condição hierarquicamente inferior ao do homem, resultado discutido como manifestação do sexismo benevolente. A oposição observada nas estruturas das representações de homossexuais e negros, também se evidencia para as mulheres, mas, no caso delas, o conteúdo apresentado as caracteriza como trabalhadoras. Destaca-se que os participantes desse estudo são, além de estudantes universitários, majoritariamente, mulheres jovens, que trabalham ou que anseiam 
participar do mercado de trabalho e que reconhecem o movimento pela igualdade de direitos das mulheres.

Para as pessoas com deficiência, a estrutura da representação também apresenta o conflito concernente a participação desse grupo no contexto de trabalho. De forma específica, envolve elementos relativos às dificuldades desse processo, à importância de o grupo ter direitos respeitados e oportunidade garantidas, ao reconhecimento do trabalho como uma forma de superação, bem como à referência a atributos profissionais valorizados no âmbito organizacional. A partir desses achados, estabeleceu-se que esse conflito decorre do reconhecimento de que as pessoas com deficiência têm direitos e atributos, que geram expectativas de participação, mas, por outro lado, as condições concretas de participação dos jovens no mercado de trabalho, favorecem uma oposição a essa participação.

Essas oposições, observadas nas estruturas das representações dos grupos supracitados, são discutidas como expressão do conflito entre valores sociais da modernidade, fundamentados no reconhecimento das leis e da pressão social, que inibem expressões abertas de preconceito, favorecendo a manifestação desse fenômeno de modo indireto.

No caso das pessoas com transtornos mentais, a estrutura das representações sugere, sobretudo, uma imagem negativa, que reconhece efetivamente a dificuldade, o preconceito, e as resistências que envolvem a participação desse grupo. Como discussão, considerou-se que as imagens associadas à loucura, que, embora venha sofrendo mudanças desde a Reforma Psiquiátrica e, desse modo, possibilitando uma maior visibilidade para o grupo, ainda autorizam formas flagrantes de preconceito contra pessoas com transtornos mentais.

Imagem ainda mais negativa é percebida na estrutura das representações acerca dos egressos do sistema prisional. A oportunidade de trabalho é mencionada junto à desconfiança e ao preconceito, o que se considera ser um limite no reconhecimento dos direitos desse grupo e uma garantia de expressão livre do preconceito, tendo em vista o estigma e as ideias fortemente compartilhadas de que esse grupo é menos merecedor de direitos e sensíveis a ações de solidariedade.

Os dados apresentados neste artigo são provenientes de uma pesquisa exploratória que faz parte de um projeto que investiga as representações sociais acerca da participação de grupos minoritários em contextos de trabalho. Esta pesquisa não está isenta de limitações. A este respeito, considera-se que o tamanho da amostra e sua característica homogênea (todos são estudantes universitários) impossibilita a generalização desses resultados. Neste sentido, estudos futuros podem vir a investigar essas representações sociais em amostras maiores e mais diversificadas da população geral. Também se faz pertinente investigar se essas representações variam em função das diferentes pertenças grupais a que os participantes fazem parte. Finalmente, acredita-se que também seja relevante investigar se existem conteúdos que não foram trazidos pelos participantes, em outras palavras, faz-se necessário analisar a zona muda das representações sociais para essas diferentes minorias, ou seja, conteúdos dessas representações que, embora sejam compartilhados pelo grupo, não se apresentam claramente nos discursos cotidianos e, por isso, requerem estratégias de investigação distintas que levem em conta essa especificidade (Menin, 2006).

Por fim, considera-se que esta pesquisa contribuiu para reflexão sobre as (in)possibilidades de participação social de minorias, especificamente no contexto de 
trabalho, tendo em vista as imagens compartilhadas acerca dos diferentes grupos, as normas e as conquistas que caracterizam suas relações sociais. Ainda, considerando os participantes desse estudo, ressaltamos a importância de a universidade constituir-se um espaço privilegiado de discussão, pesquisa e enfrentamento da violência que afeta membros de diferentes grupos sociais.

\section{Referências}

Abric, J. C. (1996). De l'importance des représentations sociales dans les problémes des l'exclusion sociale. In: J. C. Abric (Org.). Exclusion Sociale, insertion et prevention (p. 11-17). Saint-Agne: ÉRÈS.

Abric, J. C. (2001). Prácticas sociales y representaciones. México: Coyoacán.

Allport, G. W. (1954/1979). The nature of prejudice. (3a ed.). Wokingham: Addison-Wesley.

Batista, J. R. M., Leite, E. L., Torres, A. R. R., \& Camino, L. (2014). Negros e nordestinos: similaridades nos estereótipos raciais e regionais. Revista Psicologia Política, 14(30), 325-345.

Belo, R. P., \& Camino, L. (2012). Trabalho e gênero: elaborações discursivas sobre os papéis profissionais. Cadernos de Psicologia Social do Trabalho, 15(2), 271-286.

Bourdieu, P. (2012). A dominação masculina (11a ed.). Rio de Janeiro: Bertrand Brasil.

Braga, H. C., \& Pereira, J. C. (2017). A Inserção de Pessoas com Deficiência no Mercado de Trabalho: Um estudo na Cidade de São Paulo e Grande ABCD Paulista. MOMENTUM, 1(8), 159-178.

Camargo, B. V.\& Justo, A. M. (2013). IRAMUTEQ: Um software gratuito para análise de dados textuais. Revista Temas em Psicologia, Ribeirão Preto, 21(3), 513-518.

Camino L. \& Pereira C. (2000). O papel da psicologia na construção dos direitos humanos: Análise das teorias e práticas psicológicas na discriminação ao homossexualismo. Revista Perfil, 13(13), 49-69.

Camino, L., Silva, P., \& Machado, A. (2004). As novas formas de expressão do preconceito racial no Brasil: estudos exploratórios. In M. E. O. Lima \& M. E. Pereira (Orgs.). Estereótipos, Preconceitos e Discriminação: Perspectivas teóricas e Metodológicas (pp. 119-137). Salvador: EDUFBA.

Campos, P. (2003). Quando a exclusão se torna "objeto" de representações sociais. In A. Moreira \& J. Jesuíno (Orgs.), Representações sociais: teoria e prática (2a. ed., pp 103-122). João Pessoa: Ed. Universitária/UFPB.

Carrara, S., Facchini, R, Simões, J., \& Ramos, S. (2006). Política, direitos, violência e homossexualidade. Pesquisa 9a Parada do Orgulho GLBT - São Paulo 2005. Rio de Janeiro: CEPESC.

Cartilha do Censo 2010 - Pessoas com Deficiência (2012). Brasília: SDH-PR/SNPD. Recuperado em 25 setembro, 2017, de http://www.pessoacomdeficiencia.gov.br/app/sites/default/files/publicacoes/cartilha-censo2010-pessoas-com-deficienciareduzido.pdf.

Comisión Económica para América Latina y el Caribe [CEPAL]. (2016). Persiste la brecha salarial entre hombres y mujeres. Recuperado em 10 agosto, 2016, de http://www.cepal.org/sites/default/files/news/files/nota_18_brechas_salarios. pdf.

Costa, J. P., Jorge, M. S. B., Coutinho, M. P. L., Costa, E. C., \& Holanda, Í. T. A. (2016). A reforma psiquiátrica e seus desdobramentos: representações sociais dos profissionais e usuários da atenção psicossocial. Psicologia e Saber Social, 5(1), 35-45.

Costa, M. S. (2010). Trabalho informal: um problema estrutural básico no entendimento das desigualdades na sociedade brasileira. Caderno $C R H, 23(58), 171-190$.

Coutinho, B. G., França, I. S. X. D., Coura, A. S., Medeiros, K. K. A. S., \& Aragão, J. D. S. (2017). Qualidade de vida no trabalho de pessoas com deficiência física. Trabalho, Educação e Saúde, 15(2), 561-573.

Cury, C. R. J. (2002). Direito à educação: direito à igualdade, direito à diferença. Cadernos de pesquisa, 116, 245-262. 
Departamento Penitenciário Nacional [DEPEN] (2014). Levantamento Nacional de Informações Penitenciárias INFOPEN. Brasília: Ministério da Justiça.

Dias, S. (2015). A reabilitação social do apenado através do trabalho: responsabilidade empresarial no resgate da dignidade da pessoa humana. Dissertação de Mestrado. Programa de Mestrado em Direito, Universidade de Marília, São Paulo.

Doise, W. (2002). Da psicologia social à psicologia societal. Psicologia: Teoria e Pesquisa, 18(1), 27-35.

Ferreira, R. C. (2007). O gay no ambiente de trabalho: uma análise dos efeitos em ser gay nas organizações contemporâneas. Dissertação de Mestrado. Programa de Mestrado em Administração, Universidade de Brasília, Brasília.

Ferreira, R. F., \& Camargo, A. C. (2011). As relações cotidianas e a construção da identidade negra. Psicologia Ciência e Profissão, 31(2), 374-389.

Figueirêdo, M. L. R., Delevati, D. M., \& Tavares, M. G. (2014). Entre loucos e manicômios: história da loucura e a reforma psiquiátrica no Brasil. Caderno de Graduação-Ciências Humanas e Sociais-FITS, 2(2), 121-136.

Fiske, S. T., Cuddy, A. J., Glick, P., \& Xu, J. (2002). A model of (often mixed) stereotype content: competence and warmth respectively follow from perceived status and competition. Journal of personality and social psychology, 82(6), 878 - 902.

Garcia, A., \& Souza, E. M. D. (2010). Sexualidade e trabalho: estudo sobre a discriminação de homossexuais masculinos no setor bancário. Revista de Administração Pública, 44(6), 1353-1377.

Glick, P., \& Fiske, S. T. (1996). The ambivalent sexism inventory: Differentiating hostile and benevolent sexism. Journal of personality and social psychology, 70(3), 491- 512.

Guimarães, J. R. (2012). Perfil do trabalho decente no Brasil: um olhar sobre as Unidades da Federação. Brasília: OIT.

Heloani, J. R., \& Capitão, C. G. (2003). Saúde mental e psicologia do trabalho. São Paulo em Perspectiva, 17(2), 102-108.

Hernandez, A. R. C., Accorssi, A, \& Guareschi, P. (2013). Psicologia das minorias ativas: por uma psicologia política dissidente. Revista Psicologia Política, 13(27), 383-387.

Instituto Brasileiro de Geografia e Estatística [IBGE] (2011). Resultados preliminares do universo do Censo Demográfico 2010. Recuperado em 30 maio, 2016, de https://seriesestatisticas.ibge.gov.br/.

Instituto de Pesquisa Econômica Aplicada [IPEA], (2017). Mercado de Trabalho: conjuntura e análise. Brasília: IPEA - Ministério do Trabalho. Recuperado em 27 setembro, 2017, de http://www.ipea.gov.br/portal/images/stories/PDFs/mercadodetrabalho/170505_bmt_62.pdf.

Irigaray, H. A. R., Saraiva, L. A. S., \& Carrieri, A. P. (2010). Humor e Discriminação por Orientação Sexual no Ambiente Organizacional. Revista de Administração Contemporânea, 14(5), 890-906.

Jodelet, D. (1996). Représentations sociales de la maladiementale et insertion des malades mentaux. In: J. C. Abric (Org.). Exclusion Sociale, insertion et prevention (pp. 97-111). Saint-Agne: ÉRÈS.

Jodelet, D. (2001). Representações sociais: um domínio em expansão. In D. Jodelet (Org.). As Representações sociais (pp. 17-44). Rio de Janeiro: Eduerj.

Lacerda, M., Pereira, C., \& Camino, L. (2002). Um estudo sobre as formas de preconceito contra homossexuais na perspectiva das representações sociais. Psicologia: Reflexão e Crítica, 15(1), 165-178.

Lei n. 7.853, de 24 de outubro de 1999 (1999). Dispõe sobre o apoio às pessoas portadoras de deficiência, sua integração social. Brasília. 1999. Recuperado em 27 setembro, 2017, de http://www.planalto.gov.br/ccivil_03/leis/L7853.htm.

Lei n. 8.213, de 24 de julho de 1991 (1991). Dispõe sobre os Planos de Benefícios da Previdência Social e dá outras providências. Brasília. 1991. Recuperado em 27 setembro, 2017, de http://www.planalto.gov.br/ccivil_03/leis/L8213cons.htm.

Lima, M. E. O (2002). Normas Sociais e Racismo: Efeitos do Individualismo Meritocrático e do Igualitarismo na Infra-Humanização dos Negros (Tese de doutorado). Instituto Universitário de Lisboa, Portugal. 
Lima, M. E. O. (2013). Preconceito. In L. Camino, A. R. Torres, M. E. O. Lima, \& M. E. Pereira (Orgs.). Psicologia social: temas e teorias (Cap. 11, pp. 589-640). Brasília: Technopolitik.

Lima. M. E. O. \& Vala, J. (2004). As novas formas de expressão do preconceito e do racismo. Estudos de Psicologia, 9(3), 401-4011.

Lopes, O. B. (2010). Minorias, discriminação no trabalho e ação afirmativa judicial. Rev. TST, Brasília, 76(4), 149158.

López, L. C. (2012). O conceito de racismo institucional. Interface - Comunic., Saúde, Educ., 16(40), 121-34.

Maia, L. M., Camino, C., \& Camino, L. (2011). Pessoas com deficiência no mercado de trabalho: uma análise do preconceito a partir das concepções de profissionais de recursos humanos. Pesquisa e Práticas Psicossociais, 6(1), 78-91.

Martins, J. C., \& Pires, J. M. (2016). O trabalho humano na américa latina: evolução histórica e condições atuais. Cadernos PROLAM/USP, 14(27), 11-25.

Matos, M. I. \& Borelli, A. (2012). Espaço feminino no mercado produtivo. In C. B. Pinsky \& J. M. Pedro (Orgs.). Nova história das mulheres no Brasil (pp. 126-147). São Paulo: Contexto.

Medeiros, M. (2007). O trabalhador homossexual: o direito a identidade sexual e a não discriminação no trabalho. In R. R. Rios. Rompendo o silêncio: homofobia e heterossexismo na sociedade contemporânea (pp. 81-90). Porto Alegre: Nuances.

Menin, M. S. S. (2006). Representação Social e Estereótipo: A Zona Muda das Representações Sociais1. Psicologia: Teoria e Pesquisa, 22(1), 43-52.

Morin, E., Tonelli, M. J., \& Pliopas, A. L. V. (2007). O Trabalho e Seus Sentidos. Revista Psicologia \& Sociedade, 19(spe), 47-56.

Moscovici, S. (2005). Representações Sociais: Investigações em Psicologia Social. Petrópolis: Vozes.

Moscovici, S. (2009). Os ciganos entre perseguição e emancipação. Sociedade e Estado, 24(3), 653-678.

Moscovici, S. (2012). Psicanálise, sua imagem e seu público. Petrópolis: Vozes.

Organização das Nações Unidas [ONU]. (2006). Convenção Internacional sobre os Direitos das Pessoas com Deficiência. Recuperado em 25 setembro, 2017, de http://www.unfpa.org.br/Arquivos/convencao_direitos_pessoas_com_deficiencia.pdf

Pereira, A. D. S. L. S. (2009). Normas sociais, crenças sobre a natureza da homossexualidade e preconceito contra os homossexuais (Tese de doutorado) Instituto Universitário de Lisboa, Lisboa, Portugal.

Pereira, C., Torres, A. R., \& Almeida, S. (2003). Um estudo do preconceito na perspectiva das representações sociais: análise da influência de um discurso justificador da discriminação no preconceito racial. Psicologia: Reflexão e Crítica, 16(1), 95-107.

Pereira, O. M. L. (2013). A dor da cor: reflexões sobre o papel do negro no Brasil. Cadernos Imbondeiro, 2 (1), 1 5.

Pinheiro, L., Fontoura, N. D. O., Querino, A. C., Bonetti, A., \& Rosa, W. (2008). Retrato das desigualdades de gênero e raça. Brasília: IPEA.

Pocahy, F. (2007). Um mundo de injúrias e outras violações. Reflexões sobre a violência heterossexual e homofóbica a partir da experiência do CRDH. In R. R. Rios. Rompendo o silêncio: homofobia e heterossexismo na sociedade contemporânea (pp. 10-26). Porto Alegre: Nuances.

Pochmann, M. (2012). O emprego na globalização: a nova divisão internacional do trabalho e os caminhos que o Brasil escolheu. São Paulo: Boitempo Editorial.

Prado, M. A. M., \& Machado, F. V. (2008). Homossexualidades na história: alguns discursos sobre as sexualidades. In M. A. Prado \& F. V. Machado. Preconceito contra homossexualidades: a hierarquia da invisibilidade (pp. 28-42). São Paulo: Cortez

Ratinaud, P. (2009). IRAMUTEQ: Interface de R pour les Analyses Multidimensionnelles de Textes et de Questionnaires. Recuperado em 27 setembro de, 2017, de http://www.iramuteq.org. 
Resolução n. 96/2009 de 27 de Outubro do Conselho Nacional de Justiça. Diário Oficial da União: Seção 1, nº 210 (2009). Recuperado em 02 outubro, 2017, de http://www.cnj.jus.br/images/atos_normativos/resolucao/resolucao_96_27102009_10102012194748.p df.

Ribeiro, M. A., \& Carneiro, R. (2009). A inclusão indesejada: as empresas brasileiras face à lei de cotas para pessoas com deficiência no mercado de trabalho. Organizações \& Sociedade, 16(50), 545-564.

Sá, C. P. (2002). Núcleo central das representações sociais. Rio de Janeiro: Vozes.

Salles, M. M., \& Barros, S. (2013). Representações sociais de usuários de um Centro de Atenção Psicossocial e pessoas de sua rede sobre doença mental e inclusão social. Saúde e Sociedade, 22(4), 1059-1071.

Sassaki, R. K. (2010). Deficiência Psicossocial. Agenda 2011 do Portador de Eficiência. Recuperado em 19 de julho, 2016, de http://oab-j.jusbrasil.com.br/noticias/2748813/artigo-deficiencia-psicossocial-romeukazumi-sassaki.

Secretaria de Políticas para as Mulheres (2015). Relatório Anual Socioeconômico da Mulher. Brasília: Secretaria de Políticas para as Mulheres, Presidência da República.

Silva, M. D. P., \& Lussi, I. A. D. O. (2010). Geração de renda e saúde mental: o cenário do município de São Carlos. Cadernos de Terapia Ocupacional da UFSCar, 18(1), 33-48.

Tajfel, H. (1982). Social psychology of intergroup relations. Annual Review of Psychology, 33(1), 1-39.

Travis, J. (2005). But they all come back: Facing the challenges of prisoner reentry. Washington, D.C: Urban Institute Press.

Turra, C. \& Venturi, G. (1995). Racismo cordial: a mais completa análise sobre preconceito de cor no Brasil. São Paulo: Ática.

Vasconcelos, F. D. (2010). O trabalhador com deficiência e as práticas de inclusão no mercado de trabalho de Salvador, Bahia. Revista Brasileira de Saúde Ocupacional, 35(121), 41-52.

Vechi, L. G., Chirosi, P. S., \& Prado, J. N. C. (2017). A inserção social pelo trabalho para pessoas com transtorno mental: uma análise de produção científica. Revista Psicologia e Saúde, 9(1), 111-123.

Vergès, P. (1992). L'évocation de l'argent: une méthode pour la définition du noyau central d'une représentation. Bulletin de Psychologie, 45(405), 203-209.

Violante, R. R., \& Leite, L. P. (2011). A empregabilidade das pessoas com deficiência: uma análise da inclusão social no mercado de trabalho do município de Bauru, SP. Cadernos de Psicologia Social do Trabalho, 14(1), 73-91.

Volz, P. M., Tomasi, E., Bruck, N. R. V., Saes, M. O., Nunes, B. P., Duro, S. M. S., \& Facchini, L. A. (2015). A inclusão social pelo trabalho no processo de minimização do estigma social pela doença. Saúde $e$ Sociedade, 24(3), 877-886.

Wachelke, J. \& Wolter, R. (2011). Critérios de Construção e Relato da Análise Prototípica para Representações Sociais. Psicologia: Teoria e Pesquisa, 27(4), 521-526.

Wacquant, L. (2003). Punir os pobres: A nova gestão da miséria nos Estados Unidos. 2. ed. Col. Pensamento Criminológico. Rio de Janeiro: Editora Revan.

Wagner, L. C., Borba, E. C., \& Silva, M. S. (2015). Inclusão ocupacional: perspectiva de pessoas com esquizofrenia. Psicologia em Estudo, 20(1), 83-94.

Whitley, B. E., \& Kite, M. E. (2010). The Psychology of Prejudice and Discrimination (2으. Ed.). Belmont: Wadsworth \Cengage Learning. 